\title{
TYPES OF LEARNING METHODS IN ELEMENTARY SCHOOL STUDENTS
}

\author{
Parvaneh Doodman ${ }^{1 *}$ Sara Behzadi ${ }^{2}$, Seyed Javad Hashemi Ardakani ${ }^{3}$ \\ ${ }^{1}$ Faculty Member, Faculty of Economics and Social Sciences, Payame Noor University PO Box 19395-3697 \\ Tehran, Iran \\ fdoodman@gmail.com \\ ${ }^{2}$ Faculty Member, Faculty of Economics and Social Sciences, Payame Noor University PO Box 19395-3697 \\ Tehran, Iran \\ fdoodman@gmail.com \\ ${ }^{3}$ Faculty Member, Faculty of Economics and Social Sciences, Payame Noor University PO Box 19395-3697 \\ ${ }^{3}$ Tehran, Iran \\ fdoodman@gmail.com
}

\begin{abstract}
The purpose of this study was to investigate the relationship between learning methods and academic achievement in academic year 2016-2017. This is a causal-comparative research. The population of the study consisted of 298 elementary school students in the Ahl City. Using Cochran's formula and multi-stage random sampling method, 120 subjects were selected. The data gathering tool was a standard questionnaire for learning strategies based on the cognitive theory of learning by Wayne Steiner and Meyer (1986). Validity of the questionnaire was evaluated and confirmed based on the experts' point of view. Cronbach's alpha was used to calculate the reliability. The reliability of the questionnaire was 0.78 which indicates the desirable reliability of the research questionnaire. Data analysis was carried out at inferential level (multiple regression, independent group $\mathrm{T}$ test and audit analysis). The results of this study showed that there is a significant relationship between learning strategies and achievement of students in the areas of learning strategies, the elaboration strategy is highly correlated with effective development. Also, the results of T-test analysis on elaboration and monitoring strategies are significant between the two successful and unsuccessful groups. In other words, two strategies for expanding and monitoring comprehension are effective in academic achievement.
\end{abstract}

Keywords: Academic Achievement, Learning Methods, Elementary School.

\section{INTRODUCTION}

The environment around us is very complicated despite the diverse subjects, events and objects. In addition, the interaction and ongoing changes in various factors impose an increasing complexity on human life and human beings seek to find suitable solutions to deal with all these changes. Because the sources of risk and satisfaction of our needs are constantly changing. The necessary life of dynamics is the adaptability of the organism to the environment. Learning processes provide the necessary dynamics for the organism to survive under various environmental conditions in addition to recognizing various positive, negative or neutral stimuli. To learn the proper behaviors against each of the stimuli, and this learning has been undertaken in different ways since the beginning of human life, but today, with the evolution of human life, general learning and acquiring knowledge through education provide an important part of the information necessary for adaptation. (Olson and Hergenhan, 1997; translation of Seif, 2003)

When students are given formal education, they display different responses to environmental stimuli, including teaching-learning processes. In order to understand students' differences in the same education, it is necessary to study the input characteristics of learners. The emotional, physiological and cognitive characteristics of learners influence their stimuli and their way of responding. Learning methods are among these features and are one of the issues that have been considered in recent decades, especially by cognitive theorists. 
Today, cognitive theories in learning are intended to explain complex cognitive activities such as comprehension, recall, and learning styles, so that they can answer questions such as how learning occurs. How can we learn about ourselves? And how the lessons learned are stored in memory. One of the views that underlies cognitive theories is the information processing approach. In this approach, the explanation of the mental processes affecting the moment of data entry to their recall is dealt with. First, environmental stimuli (inputs) affect the organism (sensory receptors). Then it is stored for a very short time (one second) in sensory memory.

The part that is being considered is entering short-term memory and the rest is lost. The information entered into the short-term memory is transmitted using learning strategies such as Rehearsal Strategy, Elaboration Strategy and Organizational Strategy for long-term stable recording and staying there for an organized amount of life. This processing system includes two aspects of hardware and software. Sensory, short-term, and longterm memory structures make up the hardware of the mind that is intuitive and equally common in everyone. Processes such as rehearsal and elaboration are equivalent to software that people are different in how they are used and the acquisition of them is exploited. (Atkinson and Shiffrin, 1968)

As stated above, various strategies are used to record long-term memory information. These strategies include:

Educational Strategies: Strategies that the teacher uses to provide a particular subject at a specific time. Learning strategies: Strategies that the student actively uses during learning, such as mental rehearsal, elaboration, organizing, anticipating active monitoring, on their learning.

While focusing on teacher-centered learning, he focuses on his instructor and his teaching methods. His explanation of the cognitive approach based on information processing is the main focus on the learner and his learning style. He sees him as an active processor, not a passive information registrant and this is where the study method, the ability to use content, interest, intelligence and learner memory are involved. (Quoted by Wayne Stein et al., 1986)

The studies conducted in recent years indicate the importance of learning strategies in facilitating learning, recalling and recalling. The role of cognitive transformation in the use of learning strategies for rehearsal, elaboration, organizing and monitoring comprehension. For example, Meece, Bluman-Feld and Hoyle (1988) showed a positive and significant relationship between learning strategies and grade points in the university. In another study, Rodolico (2002) found that teaching learning strategies can have positive effects on academic achievement even on good learners. Flavel (1985) suggests that the level of student learning can be enhanced by reminding students how to learn, by teaching cognitive skills such as organizing information and correcting mistakes.

In spite of what we have seen, we expect our learners to study, solve, and learn a lot, but we have never taught them the right way to study problem solving and information storage. Students do not have the ability to understand concepts and books, and their progress is small. They do not have the ability to infer the meaning of a readable text and are weak in using learning strategies. Therefore, the researcher is trying to study the learning strategies of elementary students by comparing their strategies with elementary students and identifying top strategies and proposing them to education officials and educational planners to take effective steps towards enriching education and solving some educational problems.

\section{RESEARCH BACKGROUND}

\section{Internal research}

Vahedi (1997) in his study compared the learning strategies in bilingual and monolingual students, there was no significant difference between the two groups of students in using strategies. Monolingual students use rehearsal strategy more than bilingual students.

Ansari (1997) found that there is a significant relationship between high-level learning strategies and creativity, in the study of comparing learning and creativity strategies, meaning that creative people learn from high-level strategies (monitoring comprehension and organizing) 
Salarifar (1996) studied the role of meta-cognitive components in problem solving and academic achievement and concluded that metacognition has a positive and high correlation with problem solving and academic achievement. Also, the "knowledge of the person's knowledge about strategies versus the class of personal knowledge about herself and personal knowledge about the task" has the highest share in predicting the variance of academic achievement.

Aminian (1994) compared the learning methods in two groups of successful and unsuccessful students of Yazd University of Medical Sciences. In this study, the number of subjects in the successful group was 64 and in the unsuccessful group w 45 people. The research instrument was a questionnaire of 54 questions that was conducted in a group. The results of the research showed a positive and significant correlation between the learning styles and the mean scores in the university as well as the average score of the diploma and the university's average, and there was a significant difference between the two groups in terms of study and learning methods, which was successful for the group.

Baseri (1994) using strong learning strategies among strong and weak students showed that strong students use learning strategies more than poor students.

\section{Foreign Research}

Wang, Geneva, Walberg (1992) in reviewing and analyzing the content of 61 studies on the factors affecting student learning showed that, in general, 28 grades of academic achievement factors are effective. These factors were categorized into 6 large groups including: students 'attitudes, education, classroom atmosphere, background, plan, and school organization, among which the students' attitude was the most important factor affecting learning and the categories that were included in this group were:

1- Cognitive process, including: Student's ability to plan, re-evaluate and re-plan cognitive strategies that show the strongest effect on student learning.

2- Cognitive processes that have a great impact on learning, in addition to the general intelligence variable, including prior knowledge, competence and ability to read and write and verbal knowledge.

3- Emotional Learning Strategies, as the third category of this group, determines the level of effort and perseverance of the students. The effort that individual perseverance has become a key to the essential characteristics of self-control and self-regulation skills of learners.

Also Wang et al. (1992) concluded in one study that meta-cognition has a very positive effect among the 228 factors that affect learning. A study done on the first year students shows that students with high metacognition had better academic achievement.

Pentrich and De Groot (1990) in a study showed that students who were obliged to use themselves in learning through learning, organizing, and transmitting information through mental rehearsal, elaboration, and cognitive strategies than those students who use these strategies had better performance.

Ames and Archer (1988) found in their research that students with an apprenticeship goal are more interested in using self-regulatory activities, such as using cognitive strategies, planning for monitoring and helping.

Flavel (1985) states that poor students often do not care about strategy, they are not involved in metacognitive activities, and do not feel the need to engage in this.

The main purpose of teaching is to facilitate learning and is a cognitive learning that occurs in the mind of the learner and its targeted activity leads to it. Therefore, it is necessary for the learner to be studied as the main element of this process.

Intelligence, personality, previous learning, motivation and learning method, and many other factors in the learner's learning are effective, and knowing each one alone and in conjunction with each other extends our 
knowledge of learning. One of these factors is the person's learning strategy, the particular methods and techniques he deliberately uses to solve the problem and foster information (Flavel, 1976) Although numerous studies have shown that these methods are capable of being trained, most teachers and parents often think that students and students themselves find ways to study and memorize information. Therefore, with the expectation of the students to save information, there is no attempt to educate and improve study and learning methods.

For this reason, we are constantly witnessing students who are trying to learn and enjoy the same educational background as others, but do not get enough advantages. They do not succeed despite their efforts and they are constantly experiencing a defeat. In addition to imposing a high and unproductive cost of education and a repetition of education and family, it leads to negative self-concept, low self-esteem, and inefficiency in the student. I cannot, I do not want to, and motivates him to Eliminates learning. Additionally, the interaction of the emotional components mentioned with the cognitive components due to the failure of the inefficiency and the lack of favorable outcomes of education, makes this all necessary in this field necessary.

Another point that needs to be considered is how the information processing in the mind interacts with the subject of learning and research shows this relationship. Therefore, it is necessary to identify the learning strategies of students in different fields of study and to select appropriate strategies for establishing an adaptation between the learning strategy and the subject of the course. In addition, in order to achieve academic and professional success in the future, individuals need to be targeted and purposefully controlled by their people in the process of learning and study, and they will be successful in developing a proper adaptation between their learning strategies, the subject matter and the field of study, and more motivation for studying. Therefore, the research, which clarifies the relationship between the use of learning strategies, academic achievement and academic discipline, can be valuable in its role to provide planners, managers, parents and students with solutions that will increase productivity.

By comparing the results of these researches, the effect of cognitive strategies on academic achievement is revealed and the obtained information confirms the effect of teaching skills and learning techniques on improving academic achievement. However, this research does not specifically address the relationship between students' learning strategies in different fields of study and academic achievement, or at least not in spite of a lot of searches. So doing research in this case is an effective step in examining the relationship between these components. Therefore, the present study attempts to answer the following questions:

1. Is there a relationship between learning strategies and academic achievement?

2. Is there a difference between the learning strategies that students use?

\section{RESEARCH METHOD}

According to the purpose of this study, the variables studied are evaluated without any interference. This is a causal-comparative research. Comparative causative research has been suggested to research into causal relationships through the observation of a situation and the causative factors being searched in the past. In this study, academic achievement, academic success and academic failure were selected as dependent variable, and the contribution of independent variables (learning strategies) to predict their variance is determined.

\section{Society and statistical sample}

The statistical population of the study is all the elementary students of the city in the academic year of 20162017, which is equal to 298 individuals in the Lamard Education Department statistics department. The sample size was estimated using Cochran's formula of 120 people. A multi-stage random sampling method was used to select the statistical sample.

Data Gathering Tool: The tool used in this study is testing of learning strategies. This test is based on the Learning Cognitive Theory of Wayne Stein \& Meyer (1986), developed and implemented by Basiri (1995). This questionnaire contains 12 questions. 
Determining the Validity and Reliability of the Test: The validity of the construct of the questionnaire has been determined and confirmed by the factor analysis method by the supervisor and experts. The reliability of the test was calculated by Baseri (1995) and Ansari (1996) by the Cronbach alpha, which is presented in Table 1 .

Table 1. Determining the Internal Consistency of the Questionnaire by Cronbach's Alpha

\begin{tabular}{cc}
\hline $\begin{array}{c}\text { Cronbach's } \\
\text { Alpha }\end{array}$ & Learning Methods \\
& \\
\hline 0.66 & Rehearsal strategy \\
0.54 & Elaboration strategy \\
0.58 & Organizing strategy \\
0.57 & Monitoring $\quad$ on \\
& Comprehension \\
0.78 & Validity of total Test \\
\hline
\end{tabular}

Scoring Method: After completing the questionnaire, the subjects specify their answers by placing the mark (*) in the response. Responses are based on the Likert scale (including always 3, sometimes 2, and never 1), and the total score of each component is considered as the rate of use of that strategy, and the highest score for each component represents the highest use of its strategy.

\section{RESULTS AND FINDINGS}

To analyze the research data to compare the differences between independent groups of independent T-test and to find the relationship between learning strategies with academic achievement, multivariate regression analysis method, to predict success and academic failure on the scores of learning strategies, Audit analysis has been used.

\section{Question 1: Are there any relationship between learning strategies and academic achievement?}

To assess the relationship between learning strategies and academic achievement, the grades of the lesson are used as a criterion for academic achievement. The results of regression analysis are presented in Table 2 to answer the above question. As the table shows, the regression of the score is significant from the learning strategies. ( $\mathrm{F}=5.56$ and $\mathrm{df}=4$ and $\mathrm{P}<0.01)$ The correlation between learning strategies and academic achievement score is $R=0.55$. The coefficient of determination $\left(\mathrm{R}^{2}\right)$ is equal to 0.31 ; in other words, $31 \%$ of the variance of academic achievement score can be explained through learning strategies.

Table 2- Regression Analysis of Academic Achievement thought Learning Methods

\begin{tabular}{cccccccr}
\hline $\mathrm{R}^{2}$ & $\mathrm{R}$ & $\begin{array}{c}\text { Signific } \\
\text { ant level }\end{array}$ & $\mathrm{F}$ & $\begin{array}{c}\text { Average of } \\
\text { total squares }\end{array}$ & $\mathrm{df}$ & $\begin{array}{c}\text { Total } \\
\text { squares }\end{array}$ & $\begin{array}{r}\text { Changes } \\
\text { resource }\end{array}$ \\
\hline 0.31 & 0.55 & 0.001 & $\begin{array}{c}5.5 \\
6\end{array}$ & 28.030 & 4 & 112.12 & $\begin{array}{r}\text { Regressio } \\
\mathrm{n}\end{array}$ \\
& & & 5.03 & & 246.63 & \\
\hline
\end{tabular}




$\begin{array}{ll}4 & \text { Residual } \\ 9 & \end{array}$

In Table 3, the regression coefficients of each learning strategy are presented in predicting the academic achievement score. As can be seen from the table, only the elaboration strategy has a significant role in predicting the academic achievement score among the learning strategies. Therefore, the regression formula for predicting the course will be from:

$$
\mathrm{Y}=10 / 88+0 / 52(\mathrm{X})
$$

Table 3. Regression coefficients of learning strategies in predicting academic achievement

\begin{tabular}{ccccr}
\hline Significant level & $\mathrm{t}$ & $\mathrm{B}$ & $\begin{array}{c}\text { Coefficient } \\
\mathrm{b}\end{array}$ & Variable \\
\hline 0.001 & 3.87 & 0.52 & 0.170 & $\begin{array}{r}\text { Elaboratio } \\
\mathrm{n}\end{array}$ \\
& & & & Rehearsal \\
0.35 & 0.64 & 0.11 & 0.08 & $\begin{array}{r}\text { Organizin } \\
\mathrm{g}\end{array}$ \\
0.76 & 0.31 & 0.04 & 0.03 & $\begin{array}{r}\text { Monitorin } \\
\mathrm{g}\end{array}$ \\
\hline
\end{tabular}

\section{Second question: Is there a difference between the learning strategies that students use?}

To find a meaningful difference in learning strategies in the successful and unsuccessful group in each of the disciplines, the $\mathrm{T}$ test was used and the audit analysis was used to determine the contribution of each strategy in predicting success.

As Table 4 shows, the results of the T-test on elaboration and monitoring strategies are significant between the two successful and unsuccessful groups. In other words, two strategies for elaboration and monitoring comprehension are effective in academic achievement.

Table 4. T-test results among successful and unsuccessful students

\begin{tabular}{cccc}
\hline $\begin{array}{c}\text { Significant } \\
\text { level }\end{array}$ & df & $\mathrm{T}$ & Strategies \\
\hline 0.22 & 90 & -1.21 & Rehearsal \\
0.003 & 90 & -3.10 & Elaboration \\
0.52 & 90 & 0.74 & Organizing \\
0.02 & 90 & -2.34 & monitoring \\
\hline
\end{tabular}


The results of the analysis are presented in Table 5. Elaboration strategies and monitoring of the comprehension of the content are meaningful coefficients in the function of the distinctive function equation. Elaboration strategy has more academic success than forecast comprehension strategy in prediction.

Table 5. Coefficients of learning strategies in the distinctive function equation

\begin{tabular}{cc}
\hline $\begin{array}{c}\text { Coefficients in the } \\
\text { distinctive function } \\
\text { equation }\end{array}$ & Strategies \\
\hline 0.05 & Rehearsal \\
$0.15^{* *}$ & Elaboration \\
0.07 & Organizing \\
$0.133^{* *}$ & monitoring \\
\hline
\end{tabular}

\section{DISCUSSION AND CONCLUSION}

The purpose of this study was to investigate the relationship between learning methods and academic achievement of elementary school students. For this purpose, the statistical population consisted of the elementary school students in the Ahl city and 120 individuals were selected as samplesand classified as unsuccessful according to the average score of $33 \%$ as the successful group and $33 \%$ as the unsuccessful group. To collect the required information in this study, learning strategies test was used. After collecting information, regression analysis was used to test the relationship between learning strategies and academic achievement. In addition, to find meaningful difference in learning strategies in successful and unsuccessful group of $t$ test and to determine the contribution of each strategy in predicting success, the analysis was used and the results were as follows in relation to the research questions.

In examining the first question, "Are there any relationship between learning strategies and academic achievement?", We concluded that there is a significant relationship between learning strategies and academic achievement among primary school students at the level of $\mathrm{P}<0.01$. Among the learning strategies, the strategy Elaboration has a significant role in predicting academic achievement. This finding is consistent with some of the researches, including Wang et al. (1992) Kamkar (1997) Salarifar (1995) Ababaf (1995) and Aminian (1994).

According to the findings of previous studies, the results of this research can be explained in the cognitive approach. In this approach, the focus is on processes that lead to storage, classification, or retrieval in learning situations. Additionally, the learner is active in this active view of active processing that uses mental processes to cache irregular data through sensory experiences into encrypted and stored in long-term memory.

A successful student of learning is always looking for the equivalent of a clue in the cognitive process to substantially relate the material to the previously learned material. It is evident that there are proper ideas in constructing a cognition that can relate to new content and intent and the purpose of linking these thoughts is to achieve symmetrical and clues and meaningful learning, so the need for additional rehearsals is reduced and learning leads to success. In the case of a failed student simply accumulated in the minds of one another in a repetitive manner, without having a meaningful connection, it is not successful in retrieving.

While organized and systematic categories of cognitive structure are stored due to possession of clues related to long-term memory and can be retrieved for a long time, this is undoubtedly the success of a successful student in information retrieval. Successful students control meta-cognitive processes such as planning, 
evaluation, ordering, and self-reflection, but unsuccessful students, because they do not have informed control over their activities, do not specifically focus on their thinking process, and in recalling There is not much success.

In examining the second question, "Is there a difference between the learning strategies that students use?" We concluded that the results of the T-test on elaboration strategies and monitoring strategies were significant between the two successful and unsuccessful groups. In other words, two strategies for expanding and monitoring comprehension are effective in academic achievement. The results of this study are consistent with the findings of Weinstein and Meyer (1986) and Khosh Kholgh (1995).

The results of this research can be arranged that, first, successful students use different methods of expanding strategies such as summarizing mental imagery, interpreting and comparing materials in a desirable way, thereby increasing the amount of learning and its speed; while Unsuccessful students have less knowledge or less use of such strategies. Secondly, successful students actively participate in learning and change the new information in a comprehensible framework, and to do this, they use a variety of memory processes, such as categorizing, organizing, communicating, and so on.

For this reason, they are successful in remembering the contents stored in memory. But poor students do not use memory processes well and transmit information illegally to long-term memory and often encounter problems in their reminder. Thirdly, successful students are aware of their role in building knowledge. Therefore, with knowledge of the terms of the task, predict the time needed to perform the task, select the appropriate strategy and control its study method. By forecasting sample questions and asking themselves for self-monitoring, they are able to correct their ineffective strategy or replace it with another strategy.

Therefore, successful students identify deficiencies in their methods and strategies and can successfully accomplish their task at a reasonable time and at the right speed. If the unsuccessful student is concerned with knowing the task, identifying the appropriate strategy and monitoring and reviewing the performance, it is weak. This makes it possible to select a strategy with a cognitive level of cognitive tasks, that is, in terms of experiment and error, with learning task. In most cases, the mismatch of the strategy with the task of nonmonitoring and review and the inability to correct the ineffective strategy leads to failure in a learning position.

Finally, it is well-known that what's happening is not simply the link between the stimulus and the response and the repetition and reinforcement, but rather in accordance with the cognitive approach, and especially the constructive view of the learner with his active action as an active processor of the memory processes and learning is self-aware. Successful learners can be said to be strategic learners, but the important and interesting point is that these features are inherent and inherited and can be trained. As several studies clearly illustrate this fact. Teachers can thus help their students learn how to study and learn, and make sure that the fruits of this training are very promising, and many learning and transfer problems will be overcome.

In fact, with these tutorials, teacher education strategies complete the learning and learning process. Ineffective methods are identified and effective strategies are learned and used and the strategic deficiencies of the students are complemented by the teacher's training strategy. This explanation corresponds to the framework of the learning-learning process, quoted by Wayne Stein and Meyer (1986) as the basis for this research, and could be the theoretical basis for the development of a regular training program for strategic learners, in order to be effective in promoting education.

\section{RESEARCH CONSTRAINTS: THE LIMITATIONS THAT THIS STUDY FACED ARE:}

$>\quad$ The lack of access to the standard test, especially academic achievement, was therefore considered as a criterion for academic achievement.

$>\quad$ The research sample consists of elementary school students and the results are only generalizable for this community.

$>\quad$ Given the fact that the questionnaire evaluates individuals' perception of reality, then one should not ignore the possibility that such perception does not fully correspond to reality. 
The Turkish Online Journal of Design, Art and Communication - TOJDAC

ISSN: 2146-5193, March 2018 Special Edition, p. 328-337

The failure of some respondents to believe in research and their lack of importance to the results and findings of the research may not be accurate in answering the questions.

\section{RESEARCH SUGGESTIONS:}

$>\quad$ Considering the results of this research and the educational capability of learning strategies, it is recommended to develop a systematic program in the educational system for teaching these strategies.

$>\quad$ It is suggested that attention should be paid to the characteristics of cognitive tasks in writing textbooks. These tasks will be based on logic to students' age, input characteristics, cognitive and emotional learning, documentary style, achievement motivation and cognitive and metacognitive strategies of learners.

Due to the complementary role of teacher training strategies, provision of in-service training workshops for increasing the teachers' performance in teaching cognitive and meta-cognitive strategies for learners is suggested.

$>\quad$ Study methods and learning strategies as a lesson in the educational system and in different educational levels.

$>\quad$ It is suggested that academic tests be provided in all courses in order to be used as a tool for measuring academic achievement in research.

\section{ACKNOWLEDGEMENT}

We are grateful to all the education officials who have honestly helped us with this research, especially from all the staff and primary school students in the Ahl city who gave us their valuable time.

\section{REFERENCES}

Aminian, Amir Hossein (1994) Study of Learning Methods of Medical and Non-Medical Students of Shahid Sadoughi University of Yazd. Master thesis: Allameh Tabatabaei University. Faculty of Psychology and Educational Sciences.

Ansari, Roghayeh (1997) The Relationship between Learning Strategies and Students' Creativity. Master thesis, Faculty of Educational Sciences and Psychology, University of Tehran.

Baseri, Ahmad (1995) A Comparative Study of the Learning and Exercise Strategies for High School Students, Senior Thesis, Tehran: University of Tehran, Faculty of Education and Psychology.

Khosh Kholgh, Iraj (1995) The Study of the Relationship between the Purpose of Teachers with Learning Strategies and Students' Anxiety Test. Master thesis, University of Tehran, Faculty of Psychology and Educational Sciences.

Salarifar, Mohammad Hossein (1996) Investigating the role of meta-cognitive components in problem solving and academic achievement. master thesis. University of Tehran, Faculty of Psychology and Educational Sciences.

Ababaf, Zohreh (1995) Comparison of the Learning Strategies of the Strong and Weak Students in the 3rd District of Tehran. Master thesis, Allameh Tabatabaie University, Faculty of Psychology and Educational Sciences.

Kamkar, Ali (1997) Comparison of study and learning methods in two groups of strong and weak students of Yasouj University of Medical Sciences. Thesis Master of Science (MSc). Tehran University: Allameh Tabatabaei University, Faculty of Psychology and Educational Sciences.

Vahedi, Shahram (1997) Comparison of learning strategies among bilingual and single-language students. master thesis. Tehran University: Allameh Tabatabaei University, Faculty of Psychology and Educational Sciences.

Heringhan, B.R. and Olson, Matthew (2003) Introduction to Learning Theories. Translation by Ali Akbar Seif, Tehran: Publishing Duran (1997)

Ames, C. \& Archer, J. (1988). Achievement Goals in the classroom: Student's Learning strategies and Motivation processes. Journal of the Educational psychology, 80(3), 260-267.

Atkinson, R. C., Shiffrin, R. M. (1968). Chapter: Human memory: A proposed system and its control processes. In Spence, K. W., Spence, J. T. The psychology of learning and motivation. New York: Academic press. Pp. 89-195. 
The Turkish Online Journal of Design, Art and Communication - TOJDAC

ISSN: 2146-5193, March 2018 Special Edition, p. 328-337

Flavell, J. H. (1985). Metacognitive aspects of problem solving. In Renick (Ed). The Nature of intelligence. NJ; Erlboum.

Flavell, J.H.(1976). "Metacognitive Aspects of problem solving”. Resnick (Ed.) The Nature of intelligence. Hillsdale, NJ; Erlboum-PP-231-235.

Meece, J. L. Blumenfeld, P. C. \& Hoyle, R. H. (1988). Students goal orientations and cognitive engagement in classroom activities. American Psycologisits, 80(4), 514-523.

Pintrich, P-R. \& De Groot, E.V. (1990), Motivational and self- Regulated learning componets of classroom Academic performance. Jurnal of Education psycology, 81(1), 33-40.

Rodolico, J. (2002). Teaching cognitive learning strategies and vocabulary testing. Hawakang Journal of REEL, 8, 32-55.

Wang, M.C; Geneva, H.D: Walberg, H.(1992). What helps students learn? Educational leadership, 50 ,PP 7479.

Weinstein, G.E. \& Mayer, R.E. (1986). The Teaching of learning strategies, In wittrock, M.C.(Ed). Hand Book of Reserch on Teaching, CPP.315-327. New York Macmillan. 